\title{
New Markets - New Regulation: The Latin-American Experience
}

\section{Manuel Aguilera-Verduzco}

Comision Nacional de Seguros y Fianzas (CNSF), Insurgentes Sur No. 1971, Col. Guadalupe Inn, A Obregon, 01020 DF, Mexico.

E-mail: JGLopez@cnsf.gob.mx

The Latin-American Experience deals with the current situation of insurance industry in Latin America. This paper makes an initial approach to the region's macroeconomic environment, with 2000-2004 figures, recognizing the importance of market's liberalization and maturity as part of Latin America's dynamics. The main focus lies in the description of the regulatory reforms implemented in the region, as a necessary condition for a sound insurance industry, as well as a regulatory overview that makes an interesting assessment of the current situation of this industry in Latin America.

The Geneva Papers (2006) 31, 1-10. doi:10.1057/palgrave.gpp.2510058

Keywords: Latin America; insurance; regulation; supervision; regulatory reforms; supervisory authority; 2004

\section{Introduction}

Market globalization and liberalization have been the main features of the economic policy in Latin America (LA) for the last 25 years. These processes have opened the possibility of a more intense competition in the market place, through the free access of new market participants (removing entry barriers) as well as free exit (sales, merges and liquidations).

In this environment, insurance markets in $\mathrm{LA}^{1}$ have increased significantly over the last few decades. Nevertheless, the current expansion has also posed challenges for insurance supervisors on several fronts. A number of Latin-American insurance authorities have taken steps to enhance insurance regulation and supervision, and some have already developed quite sophisticated approaches to supervising insurance markets.

Generally speaking, four main factors can be associated with the development and growth dynamics of the insurance industry in LA: (1) the favourable macroeconomic environment, (2) the market liberalization process, (3) the improvement in market maturity and (4) the regulatory reforms implemented.

\footnotetext{
${ }^{1}$ In general, when referring to LA, this paper considers the following countries: Argentina, Bolivia, Brazil, Chile, Colombia, Costa Rica, Cuba, Dominican Republic, Ecuador, El Salvador, Guatemala, Honduras, Mexico, Nicaragua, Panama, Paraguay, Peru, Uruguay and Venezuela.
} 


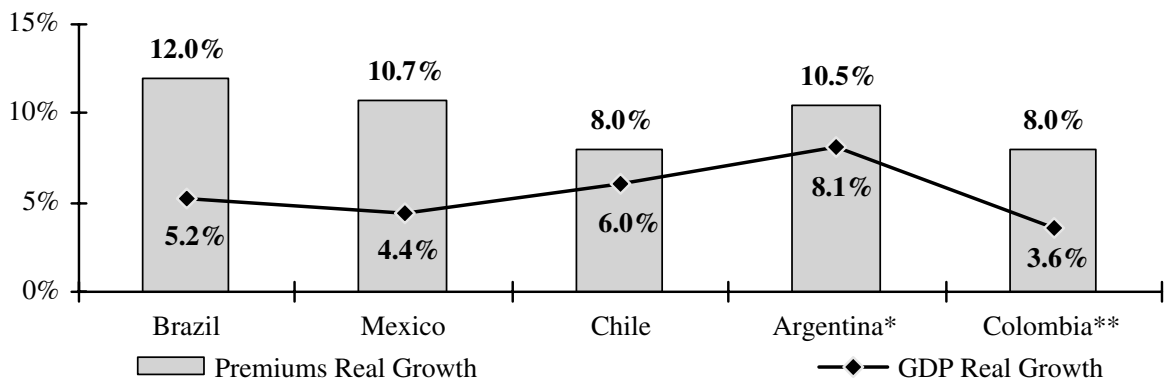

Figure 1. Total premiums and GDP real growth, 2004. Source: Supervisory authorities from Argentina, Brazil, Mexico and Chile. *June 2004 Data (premium real growth); **2003 Data Sigma 3/2004 - Swiss Re.

\section{Macroeconomic Environment}

LA is an important world region when considering its geographical extension $(20,582$ thousands of square $\mathrm{km}$, which represents nearly 14 per cent of the world's land surface) and its population (542.4 million ${ }^{2}$ in 2004 , which was 8.55 per cent of total world population in that year). The region's gross domestic product (GDP) was 1,993 USD billion, standing for 16.98 per cent of the U.S. GDP, with Mexico, Brazil, Argentina, Venezuela, Chile and Colombia being the largest economies of the region with a GDP of 659,605,153,103, 102 and 93 USD billion, respectively, representing 86 per cent of the Latin-American GDP. ${ }^{3}$

Regarding the insurance sector, total premiums summed up to 49,323 USD million (2.47 per cent of LA's GDP) in 2004, representing only 1.52 per cent of the world market. Nevertheless, real premiums grew by 10.5 per cent in real terms, the highest among all world's regions. ${ }^{4}$ Accordingly, the Latin-American main insurance markets were Brazil (18,042 USD million), Mexico (12,231 USD million), Argentina (4,098 USD million) and Chile (4,026 USD million). Those four markets represented 78 per cent of the whole region's market.

The performance of the Latin-American insurance industry in recent years has shown great dynamism. As for 2004, the premiums' growth rates in 2004 were higher than those displayed by the economy as a whole (Figure 1). Such dynamism can be explained by the effect of the entrance of new companies, the development of suitable products that fulfil the consumers' necessities, and a greater market competition.

The real growth of life premiums was 17.1 per cent, whereas non-life premiums grew by 5.9 per cent. Regarding life products, the region's main markets real growth rates were: Brazil, 16 per cent; Mexico, 21.7 per cent; Chile, 9.9 per cent; and Argentina 40.9

${ }^{2}$ For the purpose on this paper, Latin-American total population considers the following countries: Argentina, Brazil, Chile, Colombia, Costa Rica, Dominican Republic, Ecuador, El Salvador, Guatemala, Jamaica, Mexico, Peru, Trinidad and Tobago, and Venezuela.

${ }^{3}$ Swiss Re (2005).

${ }^{4}$ Swiss Re (2004) considers the following world's regions: North America, LA and Caribbean, Western Europe, Central/Eastern Europe, Japan, South and East Asia, Middle East/Central Asia, Africa and Oceania. 
per cent. As for non-life premiums, the most relevant real growth rates were: Brazil, 6.9 per cent; Mexico, 4.1 per cent; Chile, 5.0 per cent; and Argentina, 11.7 per cent.

\section{Market Liberalization}

The liberalization process has brought changes in the market structure, as well as the need for regulatory reforms. Regarding the market structure changes in LA, a sound competition by foreign insurers has allowed the development of new products and better commercial practices. The presence of competitors has also brought new technology for the insurance industry. In this competitive environment, insurers are focused in getting access to non-traditional and new markets or in specializing in certain insurance products.

The high degree of foreign strategic interest in the Latin-American insurance industry is demonstrated by the large number of foreign companies that are now present in the region (Figure 2). For instance, in 1993, there were no subsidiaries present in Mexico, whereas in early 2005, there were 45 foreign-controlled companies, holding 51.7 per cent of the premiums' share.

Concerning the need for adjusting regulatory schemes, the new dynamics of liberalization and globalization make it necessary to set up effective and efficient regulatory and supervisory frameworks. Such changes must address the need to eliminate inertial over-regulatory practices, as well as achieve the promotion of selfregulation in a pro-competitive environment.

\section{Market Maturity}

Market maturity is important when explaining the development and growth dynamics of the LA insurance industry. Usually, market maturity is associated with life insurance: the more mature a market is, the greater the share of life insurance. Life business was the fastest-growing insurance segment in Mexico, Chile and Brazil during

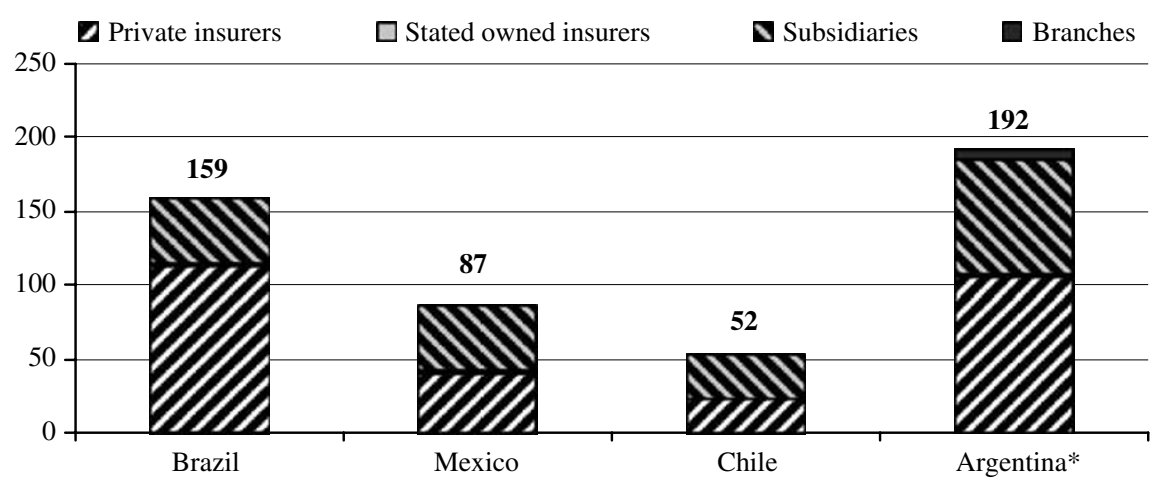

Figure 2. Market participants in LA: 2004. Source: Supervisory authorities from Argentina, Brazil, Mexico and Chile. *June 2004 Data. 


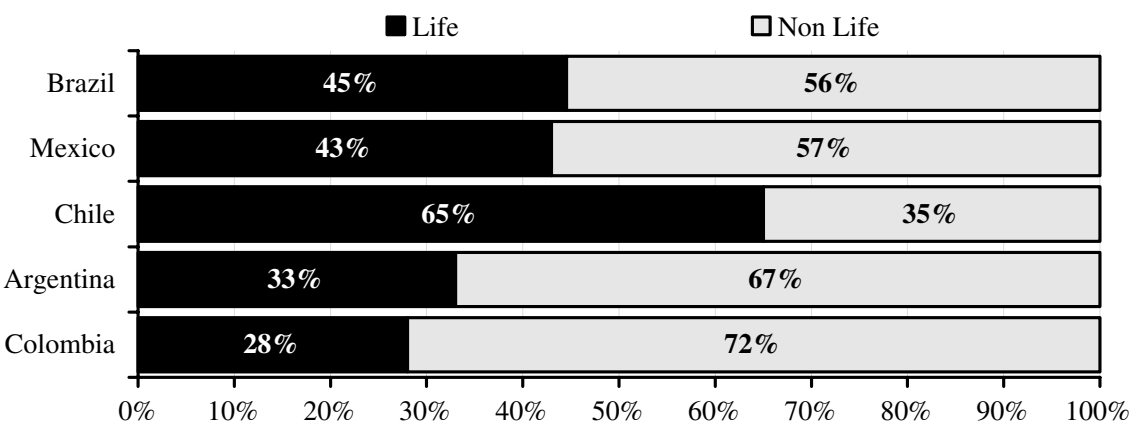

Figure 3. Insurance industry portfolio (2004). Source: Sigma No. 2/2005 - Swiss Re.

2004, Chile and Colombia being the countries that had the more significant participation of life business in the insurance portfolio (Figure 3).

Although LA is a relatively small market for insurance business, it is quite attractive for many reasons, one of them being that the region has a low insurance penetration level (premiums to GDP) when compared to developed markets, which is a sign of a big growth potential. In addition, LA's insurance expenditure is not high when compared with developed countries' insurance density, but it was higher than the average for emerging markets in 2004, which was 68.7 USD. Besides, the positive economic growth expectancy enables to foresee a strengthening of the insurance industry.

Chile and Argentina were the countries with the highest insurance penetration among the five main LA markets in 2004 (3.93 and 2.57 per cent, respectively). Regarding insurance density (premiums per capita), Brazil, Mexico, Chile, Argentina and Colombia had a higher insurance density than the emerging markets' average (Brazil, 70.69 USD; Mexico, 81 USD; Chile, 127 USD; Argentina, 92.1 USD; and Venezuela, 236.82 USD).

Regarding the dynamics of insurance density throughout 1995-2004, Mexico and Chile had a clear growing trend. In 1995, Mexico had an insurance density of 39.1 USD, which increased by 204.6 per cent for 2004. Chile's growth throughout the same period was more moderate $(60.7$ per cent), but still a significant one. On the other hand, although Brazil experienced a growing phase from 1999 to 2003 (20.2 per cent), the 1995-2004 period showed a decreasing trend. Colombia also showed a decreasing trend during the 1995-2004 period. The case of Argentina is different when considering the 2001-2002 crisis. From 1995 to 1999, insurance density grew by 25.8 per cent, but it had a sudden collapse that matches the crisis period. However, since 2003 Argentina has recovered the growing trend that it had before the crisis (Figure 4).

On the other hand, insurance penetration in Mexico, Chile, Argentina and Colombia showed a growth dynamics throughout 1995-2004, except for a decrease in 2004 in the case of Chile, and in 1999 for Colombia. Despite its growth trend, Mexico experienced a growth deceleration in that period, which was also experienced by Chile and Argentina. Brazil started the 1995-2004 period with a decreasing trend, 


\begin{tabular}{ccccc}
\hline & $\mathbf{1 9 9 5}$ & $\mathbf{1 9 9 9}$ & $\mathbf{2 0 0 3}$ & $\mathbf{2 0 0 4}$ \\
\hline Brazil & 90.1 & 68.6 & 82.5 & 70.7 \\
Mexico & 39.1 & 84.7 & 106.5 & 119.1 \\
Chile & 146.5 & 163.0 & 216.3 & 236.8 \\
Argentina* & 141.5 & 178.0 & 85.9 & 92.1 \\
Colombia** & 51.7 & 45.8 & 45.1 & n.a. \\
\hline
\end{tabular}

Figure 4. Insurance density in LA, 1995-2004. Source: Supervisory authorities from Argentina, Brazil, Mexico and Chile. *June 2004 Data; **2003 Data Sigma 3/2004 - Swiss Re.

\begin{tabular}{ccccc}
\hline & $\mathbf{1 9 9 5}$ & $\mathbf{1 9 9 9}$ & $\mathbf{2 0 0 3}$ & $\mathbf{2 0 0 4}$ \\
\hline Brazil & 2.04 & 2.10 & 2.96 & 2.10 \\
Mexico & 1.48 & 1.68 & 1.80 & 1.90 \\
Chile & 3.06 & 3.78 & 4.09 & 3.93 \\
Argentina* & 1.72 & 2.30 & 2.54 & 2.57 \\
Colombia** & 2.29 & 2.21 & 2.56 & n.a. \\
\hline
\end{tabular}

Figure 5. Insurance penetration in LA, 1995-2004. Source: Supervisory authorities from Argentina, Brazil, Mexico and Chile. *June 2004 Data; **2003 Data Sigma 3/2004 - Swiss Re.

but its 2004 insurance penetration rate was higher than that of 1995 by 3 per cent, showing a recovery in its growth dynamics (Figure 5).

\section{Regulatory Reforms in LA}

Throughout the last decade, the insurance sector in LA has experienced outstanding changes, adjusting to a new environment generated by liberalization and deregulation. Today, there is a framework of more dynamism, openness and competitiveness, which has produced important modifications in the market structure.

Therefore, insurance supervisors not only had to be aware of these changes but also have had to act accordingly. This situation has implied the need to adjust the regulatory framework, in order to (a) look after the institutions' solvency and stability; (b) protect financial service users' interest; and (c) contribute to the creation of a national and global financial stability environment.

\section{LA regulatory overview}

The Organization for Economic Co-operation and Development (OECD) released a study that sets important bases and elements for approaching an accurate regulatory assessment of the Latin-American region regarding the insurance industry. ${ }^{5}$

The OECD reports that all the countries of LA have an insurance and supervisory authority, with the exception of Costa Rica. There are many countries that also have

\footnotetext{
${ }^{5}$ OECD (2003).
} 
regulatory bodies different from their insurance supervisory authority, this being the case of Brazil, Colombia, Guatemala, Mexico, Honduras and Uruguay.

With the exception of Costa Rica, the rest of the region's countries set requirements for the establishment of insurance companies. The license for these companies must be granted by the insurance supervisory or regulatory authority. Regarding the admissibility of composite insurance companies, only nine countries (Brazil, Dominican Republic, El Salvador, Honduras, Nicaragua, Panama, Paraguay, Peru and Uruguay) accept companies that subscribe both life and non-life businesses.

Regarding subsidiaries and branches, six countries (Brazil, Costa Rica, Cuba, Dominican Republic, Guatemala and Honduras) directly restrict wholly owned subsidiaries. In the case of branches, 10 countries (Argentina, Bolivia, Brazil, Cuba, Dominican Republic, Ecuador, Honduras, Panama, Paraguay and Peru) indirectly restrict the establishment of branches, while Chile, Colombia, El Salvador, Guatemala, Mexico, Nicaragua, Uruguay and Venezuela directly restrict these kinds of establishments. The majority of Latin-American countries (except for Costa Rica and Dominican Republic) admit joint ventures under the agreement that a joint venture has a maximum limit of foreign participation.

The solvency requirements (technical reserves and capital requirements) are referred to the fact that the supervisory authority requires insurers to comply with the prescribed solvency regime, which may enable the insurer to absorb unforeseen losses. In this respect, all Latin-American countries (except for Costa Rica and Honduras) reported having adopted solvency requirements for insurance companies.

There are only four Latin-American countries where the regulation and supervision on reinsurance of direct insurance companies are not included as part of the supervisory practices (Chile, Costa Rica, Cuba and Paraguay). In this sense, Argentina, Bolivia, Brazil, Chile, Colombia, El Salvador, Guatemala, Mexico, Paraguay, Peru, Uruguay and Venezuela have a registration system for foreign reinsurers. On the other hand, domestic retention requirements are in place in Brazil, El Salvador and Guatemala. This means that the supervisory authority requires that the insurer may not cede for reinsurance abroad more than a certain percentage of the total premiums. In the case of El Salvador, the retention requirements are only applied for the earthquake line of business.

The supervisory authority of every Latin-American country (except Costa Rica) supervises the policy conditions of new products. In general, there are two types of supervision on this matter: Prior Approval (PA) and file and use (FU). In Argentina, Dominican Republic, El Salvador, Guatemala, Honduras, Nicaragua and Panama, policy conditions are subject to PA, whereas in Bolivia, Brazil, Chile, Colombia, ${ }^{6}$ Cuba, Ecuador, Mexico, Paraguay, Peru, Uruguay and Venezuela the supervision of policy conditions is a "FU" one.

The majority of the Latin-American countries supervise in a less intensive manner on premium rates in comparison to the way that they do on policy conditions. The

\footnotetext{
${ }^{6}$ In Colombia, policy conditions may be used before they are approved by the supervisory authority. This is a "UF" case.
} 
supervision of premium rates, considering the supervisory authority's PA, exists only in Argentina, Ecuador, El Salvador, Guatemala, Honduras and Nicaragua.

Regarding on-site inspections, the supervisory authority carries them out in order to examine the business of an insurer and its compliance with legislation and supervisory requirements. Costa Rica is the only Latin-American country that does not observe this type of supervision due to the already known fact of its lack of an insurance supervisory authority, whereas the whole region has also external auditors. In this sense, external auditors must be registered before the supervisory authority in most Latin-American countries, their main function being the preparation of an annual auditing report.

In Argentina, Bolivia, Brazil, Colombia, El Salvador, Nicaragua, Panama and Venezuela, the appointment or use of an actuary by insurance companies is mandatory. In Mexico, an actuary who prepares and signs technical notes and valuates technical reserves for an insurance company should be certified.

Argentina and Colombia are the only Latin-American countries that have in place a policyholders' protection fund. The majority of the countries have a preferential status of insurance companies' policyholders in the liquidation procedure (Argentina, Chile, Colombia, Ecuador, El Salvador, Guatemala, Mexico, Nicaragua, Panama, Paraguay, Peru and Venezuela).

Nearly all the countries of LA have compulsory insurances, with the exceptions of Costa Rica, Ecuador and Panama. Among the many classes of compulsory insurance, the following are the most relevant: social security, civil liability, workers' compensation, aviation insurance, public transport users insurance and automobile insurance.

In almost very Latin-American country, tax incentives for life insurance products exist, exception made for Cuba, El Salvador and Honduras. There are different tax incentives depending on the country, but, in general, these incentives are applied on life premiums, and on indemnities and earnings or capital gains from life insurance policies.

\section{Regulation and supervision: main trends}

Attending to the "public interest" principle, deregulation of financial activities must endeavour to widen management freedom of financial institutions, establish incentives for promoting auto-regulation, as well as settle new solvency control mechanisms regarding a free competition environment. In this context, establishing such control implies the necessity of having a solvency regulation, which contains standards and principles that should be in use and accepted internationally. ${ }^{7}$

Periodically, insurance supervisors are expected to carry out a self-assessment to determine whether the internationally accepted best practices are being observed in

\footnotetext{
${ }^{7}$ The International Association of Insurance Supervisors (IAIS) is the insurance supervision standardsetting body. The IAIS issues global insurance principles and standards for the supervision of the markets, whose members should strive to take into account the specific circumstances of their markets. Most of the Latin-American jurisdictions are members of the IAIS.
} 
their jurisdiction. This in turn helps in developing, prioritizing and implementing action plans that are necessary to bring out improvements.

However, while recognizing the diversity in the regulatory frameworks and supervisory approaches, it is important to take into account the domestic context, the industry structure, the stage of development of the financial system and the overall macroeconomic conditions when carrying out an assessment. The ways and means of implementation will vary across countries.

In the same direction, it is important to look at the efficiency of regulation. In general terms, the efficient level of regulation is related to the market's maturity, that is, less mature markets need more regulation (Graph 1). Therefore, efficient regulation can vary along time, based on the market maturity evolution. The important point is to avoid both an inertial over-regulatory scheme (any point at the right of the "efficient level" line) and a weak regulatory framework (any point at the left of that line).

On the other hand, best practices' compliance can also determine how financially stable or unstable an insurance market can be. Combining risk exposure and standards compliance, a general scheme can be defined (Graph 2). A high-risk exposure along with a low degree of standards compliance might end in an unstable financial situation, whereas a high degree of compliance along with a low-risk exposure can support stability in the financial markets (Graph 2).

Thus, looking at the main trends in regulation and supervision, a country with a low level of standards compliance and low support of independent third parties and corporate governance, usually implements a directive regulation, which means having more regulatory control by the supervisory authority. Advancing towards a greater compliance with international best practices and more support of independent third parties and corporate governance allows more freedom regarding insurance institutions' management, and towards establishing a solvency regulation scheme. When a country achieves a high degree of international standards compliance, its insurance industry supervision can rely more on third parties and on strong corporate

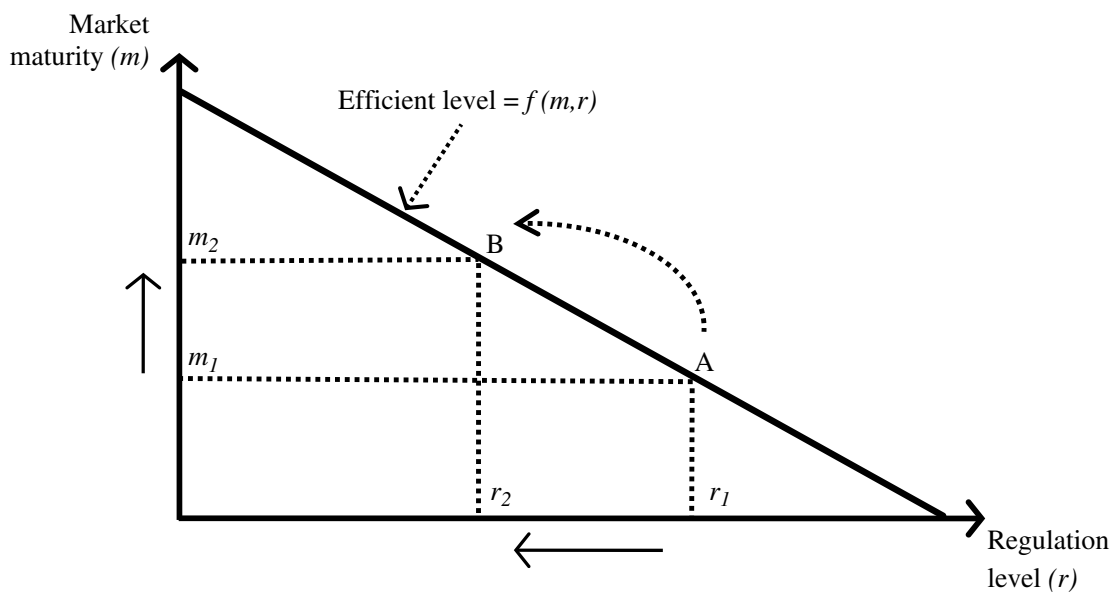

Graph 1. Market maturity vs. regulation. 


\begin{tabular}{|c|c|c|c|}
\hline \multicolumn{2}{|c|}{} & \multicolumn{2}{c|}{ Standards Compliance } \\
\cline { 2 - 4 } \multicolumn{2}{|c|}{} & Low & High \\
\hline \multirow{2}{|c|}{$\begin{array}{c}\text { Risk } \\
\text { exposure } \\
\text { (Country risk) }\end{array}$} & High & $\begin{array}{c}\text { Unstable } \\
\text { (emerging markets typical } \\
\text { situation) }\end{array}$ & $\begin{array}{c}\text { Potentially unstable } \\
\text { (situations that require } \\
\text { monitoring) }\end{array}$ \\
\cline { 2 - 4 } & Low & $\begin{array}{c}\text { Potentially unstable } \\
\text { (pre-reform situation) }\end{array}$ & $\begin{array}{c}\text { Stable } \\
\text { (mature markets } \\
\text { typical situation) }\end{array}$ \\
\hline
\end{tabular}

Graph 2. Financial stability vs. risk exposure. Source: IMF (2005).

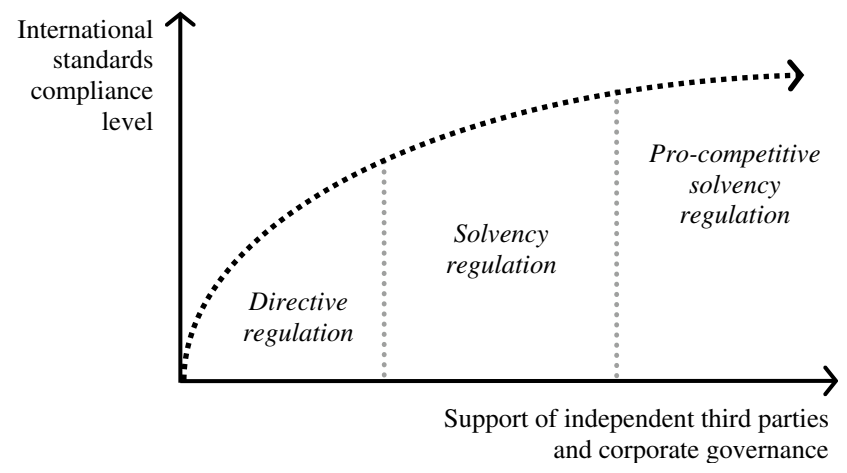

Graph 3. Regulation and supervision: main trends.

governance, thus permitting the development of a pro-competitive solvency regulation for insurers (Graph 3).

Generally speaking, and considering the characteristics of the Latin-American region, its risk exposure and its compliance with international standards on insurance supervision, it can be said that most of the LA countries are moving from a "potentially unstable" situation to a more "stable" position, and from a directive regulation scheme to a solvency regulation framework.

Given that the financial services are experiencing significant changes, regulation and supervision in the region are being adjusted to the new market circumstances. In this new context, supervision effectiveness will be increasingly based on the following elements:

- A suitable implementation of internationally accepted standards and best practices;

- a greater coordination and collaboration among supervisors (local and from other jurisdictions);

- a higher level of effectiveness and efficiency.

\section{Conclusions}

The structural changes in the region and the expected sustained growth of the economy permit to anticipate that real growth rates in the economy and in the 
10

insurance market will continue in the years to come. In this sense, the insurance sector in the region needs to sustain high growth rates, in order to reach a maturity level.

Supervisors in LA should focus their regulatory and supervisory efforts in maintaining solvency and market stability through mechanisms that are compatible with the globalization and liberalization environment. Likewise, they should react to the changing market behaviour by adjusting and improving their supervisory and regulatory frameworks. These efforts should be concentrated on seeking an efficient regulatory level and adopting best international practices.

Regarding the industry perspective, this process also implies challenges for the insurance industry in the region. Among them, there is a need to align with best international practices, as well as to have more complete and efficient technical, financial, operative and legal methods for risk management. It is also important to urge a substantial improvement in corporate governance, and achieve more disclosure and transparency mechanisms towards the market, as well as in commercial practices.

Finally, enhancing insurance culture among the population is an issue that should be given more emphasis, as it is the means by which the potential of insurance industry in LA may be attained.

\section{Acknowledgements}

I thank Norma Alicia Rosas and José Gerardo López for their help in the preparation of this paper.

\section{References}

IMF (2005) World Economic Outlook, April.

OECD (2003) Insurance Regulation and Supervision in Latin America: A Comparative Assessment, Paris: OECD.

Swiss Re (2004) Sigma, No. 3/2004.

Swiss Re (2005) Sigma, No. 2/2005.

Internet Sources:

ASSAL data in: www.assalweb.org

Supervisory Authorities' web pages from Argentina, Brazil, Mexico and Chile:

Argentina: http://www.ssn.gov.ar

Brazil: http://www.susep.gov.br

Mexico: http://www.cnsf.gob.mx

Chile: http://www.svs.cl/sitio/index.html

\section{About the Author}

Manuel Aguilera-Verduzco is the former Chairman of the International Association of Insurance Supervisors (IAIS), Vice-President of the Latin-American Association of Insurance Supervisors (ASSAL) and President of the Insurance and Surety National Commission (CNSF) of Mexico. 